\title{
Crystal Structure Imperfection of $\mathrm{LiFePO}_{4}$ Synthesized Through Solid-state Reaction: An XRD Overview
}

\author{
Ibrahim Purawiardi ${ }^{1, ~ *, ~ C h r i s t i n ~ R i n a ~ R a t r i ~}$ \\ ${ }^{1}$ Research Centre for Metallurgy and Materials, Indonesian Institute of Sciences (LIPI), South Tangerang, Indonesia \\ ${ }^{2}$ Research Centre for Physics, Indonesian Institute of Sciences (LIPI), South Tangerang, Indonesia \\ Email address: \\ rade026@lipi.go.id (I. Purawiardi), ibrahimpurawiardi@gmail.com (I. Purawiardi), christin.rina.ratri@lipi.go.id (C. R. Ratri) \\ ${ }^{*}$ Corresponding author
}

\section{To cite this article:}

Ibrahim Purawiardi, Christin Rina Ratri. Crystal Structure Imperfection of $\mathrm{LiFePO}_{4}$ Synthesized Through Solid-state Reaction: An XRD Overview. International Journal of Mineral Processing and Extractive Metallurgy. Vol. 1, No. 5, 2020, pp. 1-6.

doi: 10.11648/j.ijmpem.20200501.11

Received: March 5, 2020; Accepted: March 19, 2020; Published: March 31, 2020

\begin{abstract}
Solid-state reaction is one of some methods to synthesize $\mathrm{LiFePO}_{4}$ powder. However, the post-synthesis crystal structure was found to be imperfect, probably caused by the imperfection of the phospho-olivine structure. This study aimed to investigate the cause of its imperfection. $\mathrm{A} \mathrm{LiFePO}_{4}$ powder synthesized via solid-state reaction path was used as a case study sample for this study. XRD characterization was done to investigate it. Orthorhombic crystal structure was found to be a perfect fit for this sample using precise lattice parameter analysis, as shown by the linear regression equation result. Further analysis was performed using Rietveld refinement method to pinpoint the actual coordinates of $\mathrm{Li}, \mathrm{Fe}, \mathrm{P}$, and $\mathrm{O}$ atoms. The result shows that solid-state reaction can produce an order of orthorhombic crystal structure which constructed by ordered $\mathrm{Li}$ atoms arrangement. On the other hands, there is a disordered phospho-olivine structure due to the imperfection of the occupation of $\mathrm{Fe}, \mathrm{P}$, and $\mathrm{O}$ atoms. These disorders were found through analysis of anomalous peaks on the Rietveld refinement result when compared with PDF database. Loss of (200) plane was caused by imperfect occupation of O atoms, while imperfect occupation of $\mathrm{Fe}$ and $\mathrm{P}$ atoms leads to new (200) plane of $\mathrm{FeP}_{4}$ phase which has a monoclinic crystal structure.
\end{abstract}

Keywords: $\mathrm{LiFePO}_{4}$, Imperfection, Synthesis, Solid-state, Calcination, XRD

\section{Introduction}

$\mathrm{LiFePO}_{4}$ is a material that is widely used as a cathode active material for lithium-ion batteries [1-10]. To be able to be used as a cathode active material in lithium batteries, $\mathrm{LiFePO}_{4}$ should have phospho-olivine structure [11]. An illustration of this structure can be seen in Figure 1. Basically, the phospho-olivine structure of $\mathrm{LiFePO}_{4}$ is constructed by the bond of $\mathrm{Fe}, \mathrm{P}$ and $\mathrm{O}$. The arrangement of $\mathrm{O}$ atoms in phospho-olivine is almost close to a close-packed hexagonal structure [11]. Each of these $\mathrm{O}$ atoms is then bound to $\mathrm{Fe}$ atoms to form bonds that resemble $\mathrm{FeO}_{6}$, and some are bound to $\mathrm{P}$ atoms to form bonds that resemble POshaped tetrahedral [11]. Meanwhile, $\mathrm{Li}$ atoms are not bound to $\mathrm{Fe}, \mathrm{P}$, or $\mathrm{O}$, so they are free to move and become $\mathrm{Li}^{+}$ions [11]. With these characteristics, the crystal structure of $\mathrm{LiFePO}_{4}$ is composed of orthorhombic structural "frameworks" arranged by the arrangement of $\mathrm{Li}$ atoms, whereas in the orthorhombic structure there is an arrangement of phospho-olivine structures built from Fe-P-O $\left(\mathrm{FeO}_{6}\right.$ and $\left.\mathrm{PO}_{4}\right)$ structures as illustrated in Figure 1 [11].

However, we often find the imperfect $\mathrm{LiFePO}_{4}$ structures, especially in its phospho-olivine structure. This will probably result in poor electrochemical performance of lithium batteries when used as a cathode active material. $\mathrm{LiFePO}_{4}$ itself can be synthesized through some conventional methods such as hydrothermal [12-16], sol-gel, [17] as well as solidstate reaction [18]. Of the various reaction methods, imperfections of the $\mathrm{LiFePO}_{4}$ crystal structure are most often found in solid-state reaction path. This of course sparks its own interest to know the cause. It is however rare to find research that specifically addresses it. Therefore, this study was conducted to try to find out the common causes of imperfections in the $\mathrm{LiFePO}_{4}$ crystal structures resulting from these solid-state reactions. This study is focused on the 
crystal structure imperfections examined through $\mathrm{x}$-ray diffraction (XRD) overview.

\section{Methodology}

In this study, a sample of $\mathrm{LiFePO}_{4}$ powder synthesized by solid-state reaction was used as a case study sample. This sample was synthesized from raw materials i.e. $\mathrm{LiOH}_{2} \mathrm{H}_{2} \mathrm{O}$ powder, $\mathrm{Fe}_{2} \mathrm{O}_{3}$ powder, and liquid $\mathrm{H}_{3} \mathrm{PO}_{4}$. These materials were mixed evenly then ground using mortar and pestle. After that, the sample was synthesized by the solid-state reaction method through three step calcinations i.e. $700^{\circ} \mathrm{C}$ for 2 hours, $800^{\circ} \mathrm{C}$ for 8 hours, and ended with inert calcination together with activated carbon tablets with the parameter of $800^{\circ} \mathrm{C}$ for 2 hours. Accumulatively, the whole reaction follows the following equation below:

$$
\begin{aligned}
& 4 \mathrm{LiOH}_{2} \mathrm{H}_{2} \mathrm{O}_{(\mathrm{s})}+2 \mathrm{Fe}_{2} \mathrm{O}_{3(\mathrm{~s})}+4 \mathrm{H}_{3} \mathrm{PO}_{4(\mathrm{l})}+n \mathrm{C}_{(\mathrm{s})} \rightarrow \\
& 4 \mathrm{LiFePO}_{4(\mathrm{~s})}+(n-1) \mathrm{C}_{(\mathrm{s})}+\mathrm{CO}_{2(\mathrm{~g})}+12 \mathrm{H}_{2} \mathrm{O}_{(\mathrm{g})}
\end{aligned}
$$

The solid-state reaction then produces $\mathrm{LiFePO}_{4}$ powder and residual of activated carbon tablets that do not react with oxygen. The $\mathrm{LiFePO}_{4}$ powder was then separated from the remaining activated carbon tablets so that pure $\mathrm{LiFePO}_{4}$ powder was obtained as a result of solid-state reaction. This $\mathrm{LiFePO}_{4}$ powder was then used as a case study sample for this study.

This sample was then characterized by Rigaku SmartLab 3 kW X-ray Diffractometer (XRD) with Cu-tube $(\lambda=1.541862$ $\AA$ ) to investigate the imperfect crystal structure. The range of $2 \theta$ used is $10^{\circ}-90^{\circ}$.

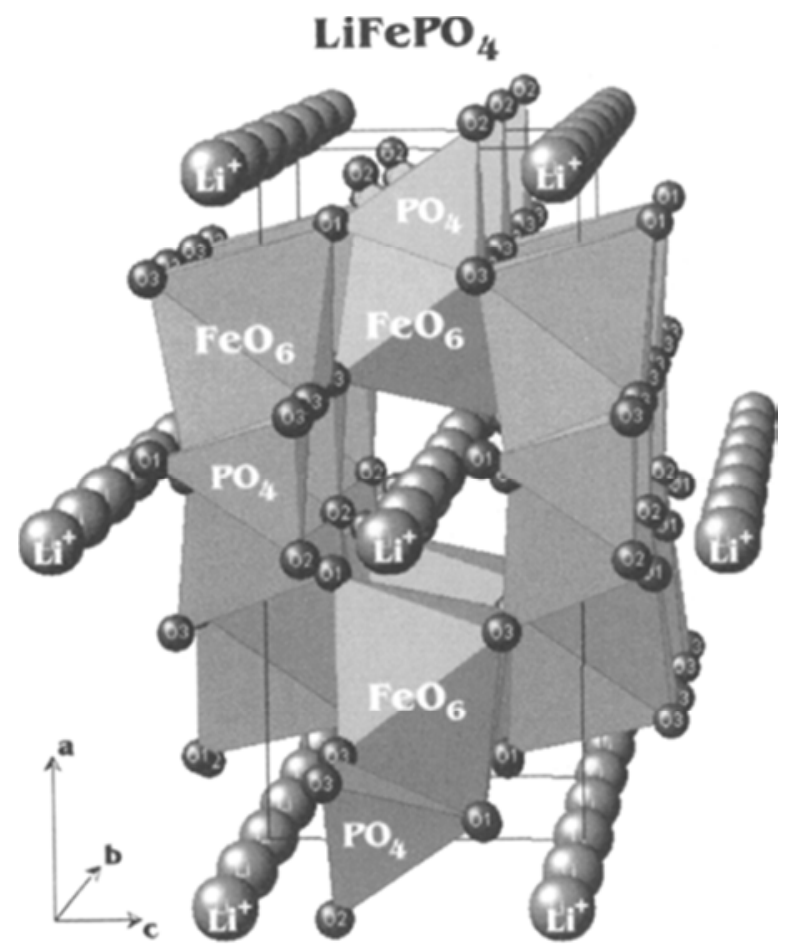

Figure 1. Illustration of phospho-olivine $\mathrm{LiFePO}_{4}$ structure [11].

\section{Results and Discussion}

\subsection{Precise Lattice Parameter Analysis}

The list of $2 \theta$ and $d$ ( $d$-spacing) as important parameters of XRD characterization results can be seen in Table 1. This list showed matching $d$ values when compared with the $\mathrm{LiFePO}_{4}$ phase reference (PDF No. 01-080-6319), indicating the formation of $\mathrm{LiFePO}_{4}$ with orthorhombic crystal structure (see Table 1).

However, to prove it, it is first necessary to do an analysis to identify the orthorhombic crystal structure in the sample of this case. An orthorhombic investigation was performed using Lutts' analytical method [19]. The result of Lutts' analytical method apparently did show the orthorhombic crystal structure $\left(a \neq b \neq c, \alpha=\beta=\gamma=90^{\circ}\right)$. The complete calculation result in the form of planes $(h k l)$ and lattice parameters $(a, b, c)$ can be seen in Table 2 .

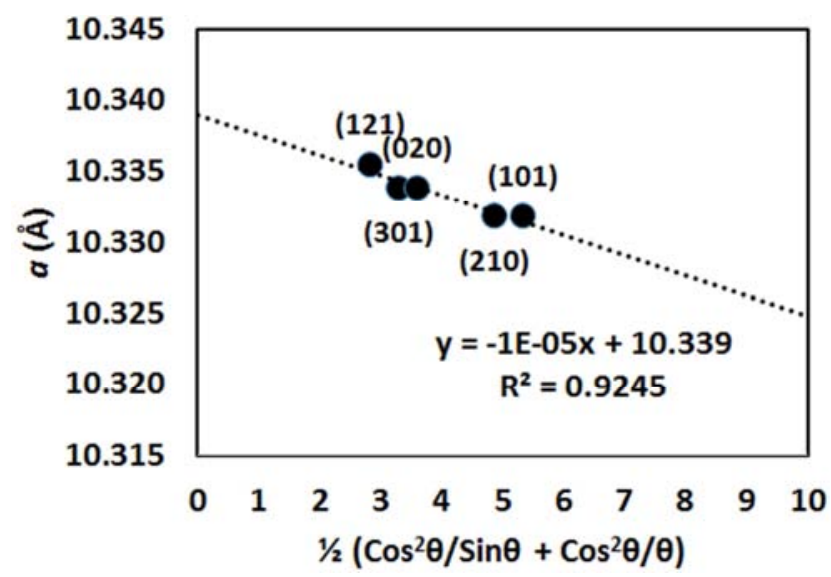

Figure 2. Linear regression analysis for calculating precise lattice parameter $\left(a_{0}\right)$ of orthorhombic crystal structure.

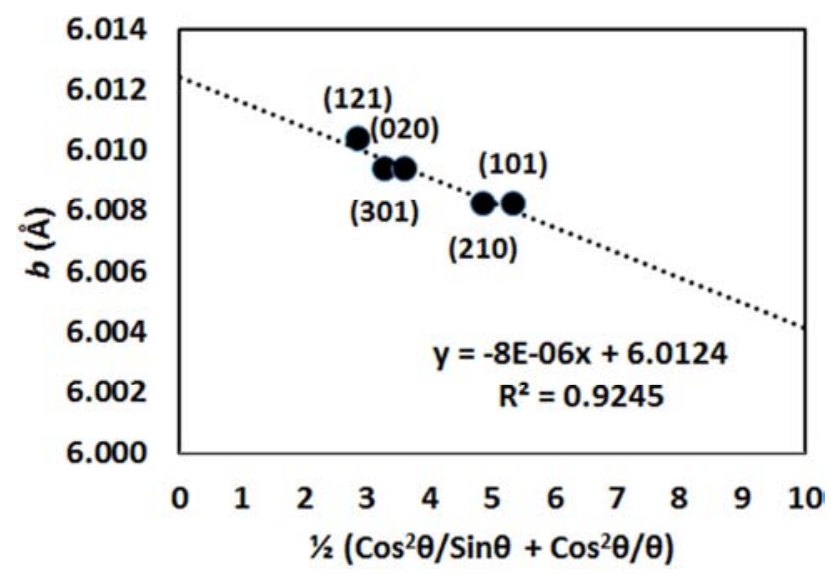

Figure 3. Linear regression analysis for calculating precise lattice parameter $\left(b_{o}\right)$ of orthorhombic crystal structure.

Table 2 shows that orthorhombic lattice parameter values $(a, b$, and $c$ ) shows different values at different $2 \theta$ angle. This is because the lattice parameter values are pseudo-lattice parameter values. The value of this pseudo-lattice parameter varies depending on the $2 \theta$ point of view. Therefore, it is necessary to do an analysis to find out the true lattice 
parameter values of the detected orthorhombic crystal structure. The true lattice parameter values can be calculated using the Nelson-Riley analytical technique [20]. The actual true lattice parameter value is then referred to as the precise lattice parameter value (symbolized by $a_{0}, b_{0}$, and $c_{\mathrm{o}}$ ) [20]. Based on the distribution of pseudo-lattice parameter values in Table 2, the precise lattice parameter values are then calculated and the results are obtained in the form of linear regression equations as shown in Figure 2, Figure 3, and Figure 4.

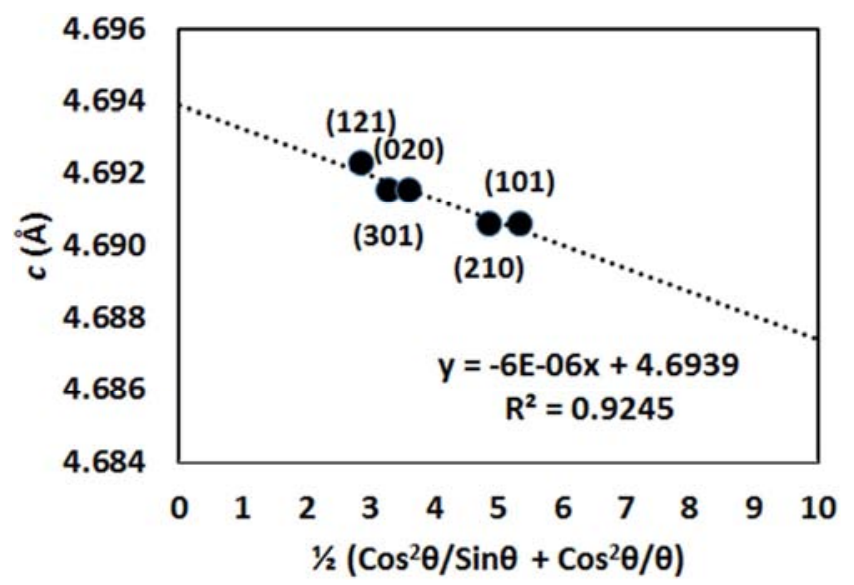

Figure 4. Linear regression analysis for calculating precise lattice parameter $\left(c_{o}\right)$ of orthorhombic crystal structure.

In this precise lattice parameter analysis, the first thing to be noted is that the resulting linear regression line must be valid. The validity of linear regression line can be identified from the $R^{2}$ value. This value should ideally be 1 (one), but for real conditions it is sufficient to meet the range of $0.9 \leq$ $R^{2} \leq 1$ only. Equations plotted on Figure 2, Figure 3, and Figure 4 show the $R^{2}$ value of 0.9245 , which means the resulting linear regression equation is valid for use. Furthermore, calculation results show that the orthorhombic crystal structure detected has precise lattice parameters of $a_{o}$ $=10.339 \AA, b_{o}=6.0124 \AA$ and $c_{o}=4.6939 \AA$ (indicated by the intersection point on the $y$-axis in Figure 2, Figure 3, and Figure 4). These values possess close similarity with the lattice parameter values of $\mathrm{LiFePO}_{4}$ phase reference (PDF No. 01-080-6319; $a=10.32 \AA, b=6.0068 \AA, c=4.6993 \AA$ ).

Next, we look back at Figure 2, Figure 3, and Figure 4. The linear regression lines formed are contributed by (101), (210), (020), (301), and (121) planes only. Other planes i.e. (111), (311), (222), and (512) do not contribute to the linear regression lines. A linear regression line basically shows an order of unit-cell of crystal structure, in this case orthorhombic crystal structure. Orthorhombic crystal structure formed in this case is only composed by (101), (210), (020), (301), and (121) planes only.

When traced deeper into the five constituent planes of this orthorhombic crystal structure of $\mathrm{LiFePO}_{4}$, these planes are significantly contributed by the arrangement of $\mathrm{Li}$ atoms, as seen on Figure 5. Thus, the orthorhombic crystal structure identified from the calculation of the precise lattice parameter is the orthorhombic "frame" structure composed by Li atoms.
The illustration of this orthorhombic structural "framework" can be seen in Figure 6.

Table 1. XRD characterization result and phase probability of $\mathrm{LiFePO}_{4}$.

\begin{tabular}{lll}
\hline XRD Characterization Result & $\begin{array}{l}\text { Phase Reference of } \mathrm{LiFePO}_{\mathbf{4}} \text { (PDF } \\
\text { No. 01-080-6319) }\end{array}$ \\
\hline $\left.\mathbf{2 \theta} \mathbf{(}^{\circ}\right)$ & $\boldsymbol{d}(\boldsymbol{\AA})$ & $\boldsymbol{d}(\boldsymbol{\AA})$ \\
\hline 20.7980 & 4.271039 & 4.27677 \\
22.7013 & 3.917075 & 3.91412 \\
25.5950 & 3.480408 & 3.48394 \\
29.7340 & 3.004687 & 3.00340 \\
32.2407 & 2.776570 & 2.77577 \\
35.6280 & 2.519976 & 2.51974 \\
36.5570 & 2.458042 & 2.45787 \\
52.4419 & 1.744843 & 1.74197 \\
61.8502 & 1.500108 & 1.50170 \\
\hline
\end{tabular}

Table 2. Lutts' analytical method result for orthorhombic analysis.

\begin{tabular}{lllll}
\hline $\left.\mathbf{2 \theta} \mathbf{(}^{\circ}\right)$ & $\boldsymbol{h} \boldsymbol{k}$ & $\boldsymbol{a}(\boldsymbol{\AA})$ & $\boldsymbol{b}(\boldsymbol{\AA})$ & $\boldsymbol{c}(\boldsymbol{\AA})$ \\
\hline 20.7980 & 101 & 10.331766 & 6.008205 & 4.690591 \\
22.7013 & 210 & 10.331768 & 6.008206 & 4.690592 \\
25.5950 & 111 & 10.329693 & 6.006999 & 4.689650 \\
29.7340 & 020 & 10.333776 & 6.009374 & 4.691504 \\
32.2407 & 301 & 10.333803 & 6.009389 & 4.691516 \\
35.6280 & 311 & 10.331519 & 6.008061 & 4.690479 \\
36.5570 & 121 & 10.335455 & 6.010350 & 4.692266 \\
52.4419 & 222 & 10.357234 & 6.023015 & 4.702154 \\
61.8502 & 512 & 10.323952 & 6.003660 & 4.687044 \\
\hline
\end{tabular}

\subsection{Rietveld Refinement Analysis}

The orthorhombic structure that has been calculated is known to be formed only by the arrangement of $\mathrm{Li}$ atoms only, while we know the structure of $\mathrm{LiFePO}_{4}$ is of course also composed of $\mathrm{Fe}, \mathrm{P}$, and $\mathrm{O}$ atoms in addition to the $\mathrm{Li}$ atom. Since only orthorhombic "frame" structure of Li atoms has been identified, it can only be ascertained that there are $\mathrm{Li}$ atoms in $(0,0,0)$ coordinates. Meanwhile, to ensure the formation of phospho-olivine structures within the "framework" of the orthorhombic structure, it is necessary to first ascertain the actual coordinates of the $\mathrm{Fe}, \mathrm{P}$, and $\mathrm{O}$ atoms. Furthermore, for knowing the actual coordinates of the $\mathrm{Fe}, \mathrm{P}$ and $\mathrm{O}$, we can do a simulation using the Rietveld refinement method [21].

This simulation is carried out until a convergent condition is reached between the observation results with the calculation of the Rietveld method. Besides achieving convergence, this simulation is also carried out until the lattice parameter values of $a, b$, and $c$ are equal or close to the results of the $a_{o}, b_{o}$ and $c_{o}$ analysis results of the previous precise lattice parameter analysis. The result of the Rietveld refinement simulation can be seen in Figure 7. Convergence was achieved at $c h i^{2}=1.158$ and $w R p=$ $10.53 \%$. Statistically, this condition is convergent enough to observe the simulation result. In this convergent condition, the lattice parameter values obtained are $a=10.330258 \AA, b=$ $6.005805 \AA$ and $c=4.695306 \AA$. These are very close to the values of precise lattice parameters from previous calculation that is $a_{o}=10.339 \AA, b_{o}=6.0124 \AA$ and $c_{o}=4.6939 \AA$. 
Table 3. Occupation coordinates of $\mathrm{Li}, \mathrm{Fe}, \mathrm{P}$, and $\mathrm{O}$ atoms from Rietveld refinement simulation.

\begin{tabular}{lllll}
\hline Atom & $\boldsymbol{x} / \boldsymbol{a}$ & $\boldsymbol{y} / \boldsymbol{b}$ & $\boldsymbol{z} / \boldsymbol{c}$ & Occupation \\
\hline $\mathrm{Li}$ & 0.000000 & 0.000000 & 0.000000 & 1.0000 \\
$\mathrm{Fe}$ & 0.281317 & 0.250000 & 0.958766 & 0.8567 \\
$\mathrm{P}$ & 0.092807 & 0.250000 & 0.394131 & 0.4477 \\
$\mathrm{O}$ & 0.095833 & 0.250000 & 0.626202 & 1.0000 \\
$\mathrm{O}$ & 0.486515 & 0.250000 & 0.228455 & 1.0000 \\
$\mathrm{O}$ & 0.160234 & 0.050603 & 0.275679 & 1.0000 \\
\hline
\end{tabular}

Table 4. Occupation coordinates of $\mathrm{Li}, \mathrm{Fe}, \mathrm{P}$ and $\mathrm{O}$ atoms of phosphoolivine $\mathrm{LiFePO}_{4}$ reference (PDF No. 01-080-6319).

\begin{tabular}{lllll}
\hline Atom & $\boldsymbol{x} / \boldsymbol{a}$ & $\boldsymbol{y} / \boldsymbol{b}$ & $\boldsymbol{z} / \boldsymbol{c}$ & Occupation \\
\hline $\mathrm{Li}$ & 0.00000 & 0.00000 & 0.00000 & 1.0000 \\
$\mathrm{Fe}$ & 0.28222 & 0.25000 & 0.97472 & 1.0000 \\
$\mathrm{P}$ & 0.09486 & 0.25000 & 0.41820 & 1.0000 \\
$\mathrm{O}$ & 0.09678 & 0.25000 & 0.74279 & 1.0000 \\
$\mathrm{O}$ & 0.45710 & 0.25000 & 0.20602 & 1.0000 \\
$\mathrm{O}$ & 0.16558 & 0.04646 & 0.28478 & 1.0000 \\
\hline
\end{tabular}

After convergent conditions are achieved, we can then pay attention to the simulation results of the coordinates/atom positions. These coordinates can be seen in Table 3. If we compare it with the atomic occupancy coordinates in the reference of phospho-olivine $\mathrm{LiFePO}_{4}$ structure (see table 4), we can see that only Li atoms have similar actual coordinates as the reference, unlike $\mathrm{Fe}, \mathrm{P}$, and $\mathrm{O}$ atoms. This further strengthens the notion that the ordered structure is formed by the arrangement of $\mathrm{Li}$ atoms only, which forms the orthorhombic "frame" structure. Meanwhile, the phosphoolivine structure which is expected to form on the inside of the orthorhombic structural space is thought to be still not visible because the coordinates of the $\mathrm{Fe}, \mathrm{P}$ and $\mathrm{O}$ atoms are not in accordance with the standard reference of $\mathrm{LiFePO}_{4}$ which has a phospho-olivine structure.

\subsection{Predicted Causes of Phospho-olivine Structural Failure}

If we look at the occupancy values in Table 3, only Li and $\mathrm{O}$ atoms have full occupancy value of 1 (one); they are numbered in a unit-cell according to the $\mathrm{LiFePO}_{4}$ standard reference (PDF No. 01-080-6319). Meanwhile, Fe and P atoms have occupancy values below 1 (one). This shows that the number of $\mathrm{Fe}$ and $\mathrm{P}$ atoms in an expected $\mathrm{LiFePO}_{4}$ unitcell is not in accordance with the reference of $\mathrm{LiFePO}_{4}$ which has a phospho-olivine structure (PDF No. 01-080-6319).

Table 5. Phase probability of $\mathrm{FeP}_{4}$ based on reference.

\begin{tabular}{lll}
\hline XRD Characterization Result & & Phase Reference of FeP $\mathbf{~}^{(P D F 2 ~ N o . ~ 79-0486)}$ \\
\hline $\mathbf{2 \theta}\left({ }^{\circ}\right)$ & $\boldsymbol{d}(\boldsymbol{\AA})$ & $\boldsymbol{d}(\boldsymbol{\AA})$ and $(\boldsymbol{h k l})$ \\
\hline 20.7980 & 4.271039 & - \\
22.7013 & 3.917075 & - \\
25.5950 & 3.480408 & $3.4820(112)$ \\
29.7340 & 3.004687 & $3.0094(023)$ \\
32.2407 & 2.776570 & $2.7614(131)$ \\
35.6280 & 2.519976 & $2.5266(200)$ \\
36.5570 & 2.458042 & $2.4428(024)$ \\
52.4419 & 1.744843 & $1.7409(224)$ \\
61.8502 & 1.500108 & $1.5016(\overline{1} 17)$ \\
\hline
\end{tabular}

If all $\mathrm{Li}, \mathrm{Fe}, \mathrm{P}$ and $\mathrm{O}$ atoms had an occupancy value of 1 (one), then the formula formed would be $\mathrm{Li}_{1} \mathrm{Fe}_{1} \mathrm{P}_{1}\left(\mathrm{O}_{4}\right)_{1}$ or $\mathrm{LiFePO}_{4}$. However, in actual conditions, the occupancy values of $\mathrm{Fe}$ and $\mathrm{P}$ were 0.8567 and 0.4477 (see Table 3), resulting in the formula of $\mathrm{LiFe}_{0.8567} \mathrm{P}_{0.4477} \mathrm{O}_{4}$. This shows that the $\mathrm{LiFePO}_{4}$ formula failed to form due to the loss of $\mathrm{Fe}_{(1-}$ ${ }_{0.8567)} \mathrm{P}_{(1-0.4477)}$ or simplified to $\mathrm{Fe}_{0.1433} \mathrm{P}_{0.5523}$.

$\mathrm{Fe}_{0.1433} \mathrm{P}_{0.5523}$ formula is very close to the $\mathrm{Fe}_{0.14} \mathrm{P}_{0.56}$ formula, respectively. $\mathrm{Fe}_{0.14} \mathrm{P}_{0.56}$ formula is actually $0.14 \times$ $\mathrm{FeP}_{4}$, so the prediction of the actual whole reaction that occurs is as follows:

$$
\begin{gathered}
4 \mathrm{LiOH} . \mathrm{H}_{2} \mathrm{O}(\mathrm{s}) \\
+2 \mathrm{Fe}_{2} \mathrm{O}_{3(\mathrm{~s})}+4 \mathrm{H}_{3} \mathrm{PO}_{4(\mathrm{l})}+n \mathrm{C}_{(\mathrm{s})} \rightarrow \\
4 \mathrm{LiFe}_{0.86} \mathrm{P}_{0.44} \mathrm{O}_{4(\mathrm{~s})}+0.56 \mathrm{FeP}_{4(\mathrm{~s})}+(n-1) \mathrm{C}_{(\mathrm{s})}+ \\
\mathrm{CO}_{2(\mathrm{~g})}+12 \mathrm{H}_{2} \mathrm{O}_{(\mathrm{g})}
\end{gathered}
$$

From the predicted actual reaction (2) it is clearly seen that failure of phospho-olivine structure formation in $\mathrm{LiFePO}_{4}$ is caused by incomplete reaction of unreacted $\mathrm{Fe}$ and $\mathrm{P}$ during solid-state synthesis. Instead of forming expected $\mathrm{LiFePO}_{4}, \mathrm{Fe}$ and $\mathrm{P}$ bond together to form $\mathrm{FeP}_{4}$. From phase point of view, $\mathrm{FeP}_{4}$ has monoclinic crystal structure (PDF2 No. 79-0486).
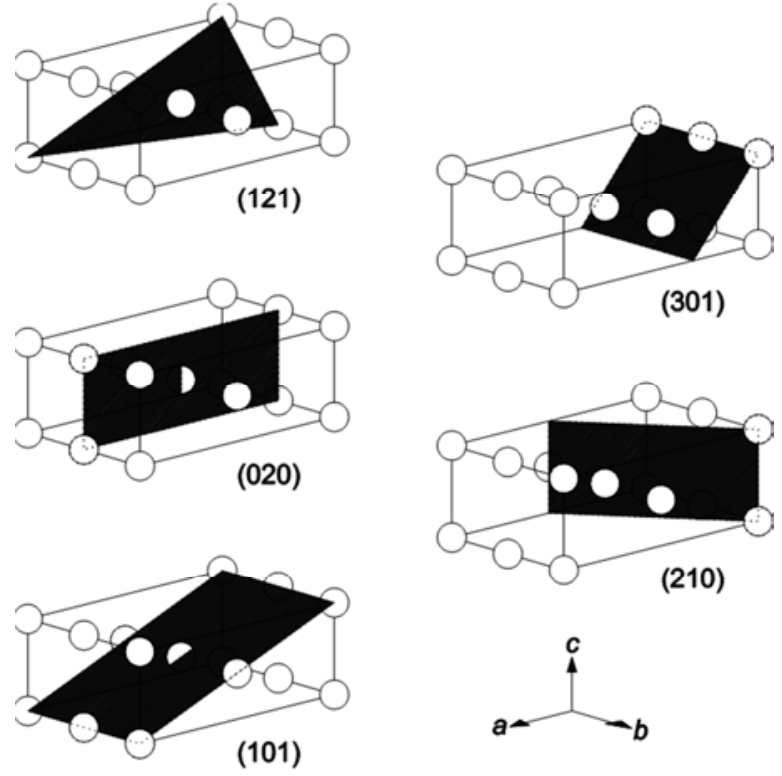

Figure 5. Illustration of some planes constructed by Li atoms arrangement on orthorhombic "frame" of $\mathrm{LiFePO}_{4}$ crystal structure. 
Looking at XRD observation results, there are seven $\mathrm{FeP}_{4}$ diffraction line probabilities (see Table 5). However, to ascertain the exact location of the $\mathrm{FeP}_{4}$ crystal structure, it can be investigated from some anomalies in the Rietveld refinement error distribution. These anomalies are marked with number 1 and 2 in Figure 7.

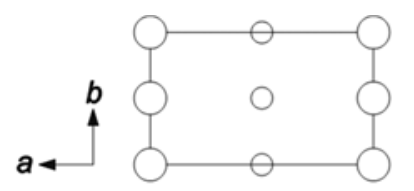

\section{Li atom}
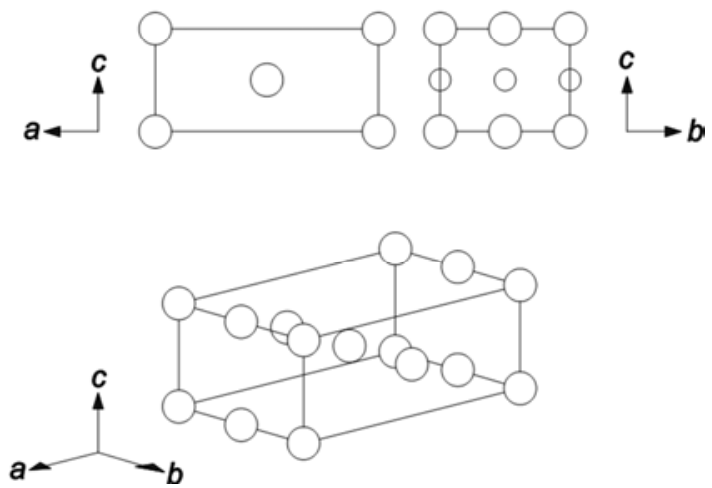

Figure 6. Illustration of Orthorhombic "frame" composed by arrangement of Li atoms.
These two anomalies are at $d=2.519976 \AA$ and $d=5.16$ $\AA$. At $d=5.16 \AA$; no convergence was found between observations and calculations result. This is caused by the non-detected value of $d=5.16 \AA$ on the observation results. The value of $d=5.16 \AA$ itself indicates the (200) plane in the phospho-olivine $\mathrm{LiFePO}_{4}$ structure (PDF No. 01-080-6319). Thus, this indicates a failure in the formation of (200) plane in the resulting $\mathrm{LiFePO}_{4}$ structure. The failure to form (200) plane is only possible due to imperfect occupancy of the $\mathrm{O}$ atoms. Meanwhile, the anomaly that occurs at $d=2.519976$ $\AA$ is probably caused by the addition of an additional preferred orientation from another phase beside $\mathrm{LiFePO}_{4}$. If we look at the probabilities in Table 5, in the range of $d$ values there is a possible (200) plane of the $\mathrm{FeP}_{4}$ phase which has a monoclinic crystal structure. From these two anomalous analysis, it can be assumed that the failure of the formation of phospho-olivine structure in the "framework" of orthorhombic structure is caused by the imperfections of occupational coordinates of $\mathrm{Fe}, \mathrm{P}$ and $\mathrm{O}$ atoms, where imperfect coordinates of occupancy of the $\mathrm{O}$ atoms cause loss of (200) plane, which should be one of the planes forming the structure of phospho-olivine. Failure of occupancy of some $\mathrm{Fe}$ and $\mathrm{P}$ atoms consequently leads to the emergence of new (200) plane of another structure i.e. $\mathrm{FeP}_{4}$ phase which has a monoclinic crystal structure.

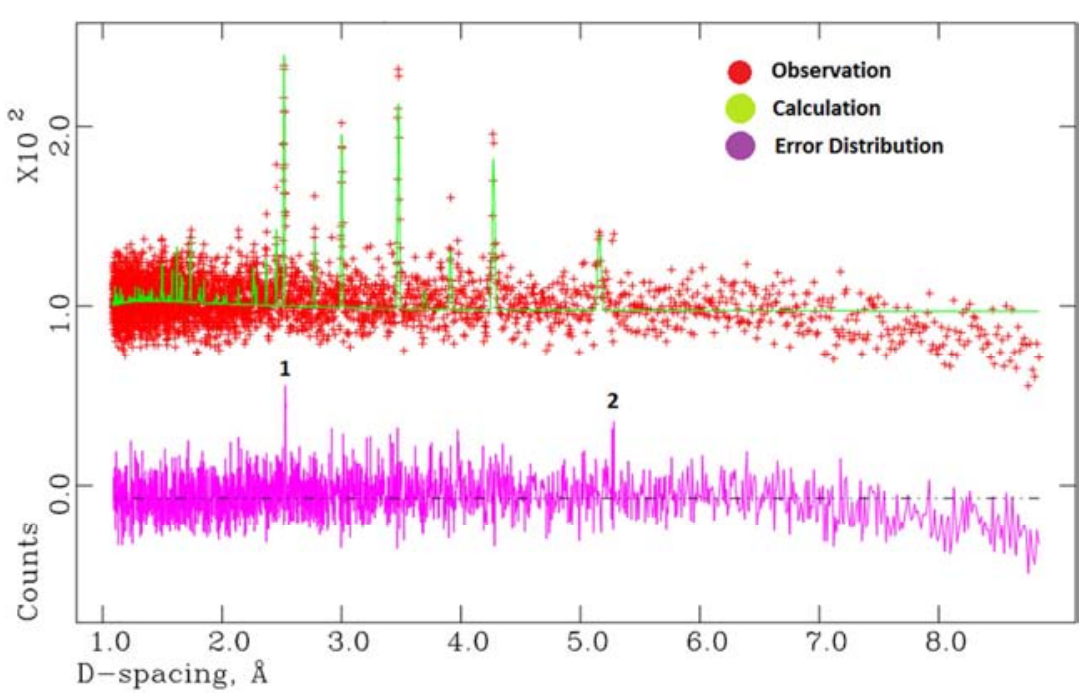

Figure 7. Rietveld refinement result of $\mathrm{LiFePO}_{4}$ powder diffraction pattern.

\section{Conclusion}

Based on this XRD investigation, it can be concluded that there are two main factors causing imperfections of the structure of the phospho-olivine $\mathrm{LiFePO}_{4}$ synthesized by solid-state reaction. The first factor is the imperfection in the occupancy coordinates of the $\mathrm{O}$ atoms, causing loss of (200) plane which should be one of the parts of the phospho-olivine structure. Whereas the second factor is occupancy failure of some $\mathrm{Fe}$ and $\mathrm{P}$ atoms which instead form a new crystal structure of monoclinic $\mathrm{FeP}_{4}$ with a single (200) plane.

From the investigation of the $\mathrm{LiFePO}_{4}$ powder as a case study sample, although the structure of the phospho-olivine failed to form completely, the orthorhombic "frame" structure was formed perfectly by the arrangement of $\mathrm{Li}$ atoms.

\section{Acknowledgements}

This research is a part of the lithium battery research and development project at the Research Centre for Physics LIPI funded by the Ministry of Research, Technology and Higher Education (Kemenristekdikti), Republic of Indonesia through the 2016 "Insinas" program. 


\section{References}

[1] N. D. Rago, J. Li, Y. Sheng, D. L. Wood, L. A. Steele, J. Lamb, C. Grosso, K. Fenton, I. Bloom. "Effect of Binder on the Overcharge Response in $\mathrm{LiFePO}_{4}$-containing Cells," Journal of Power Sources, vol. 450, pp. 227595, Feb. 2020. DOI: 10.1016/j.jpowsour.2019.227595.

[2] Q. Liang, H. Yue, S. Wang, S. Yang, K. H. Lam, X. Hou. "Recycling and Crystal Regeneration of Commercial Used $\mathrm{LiFePO}_{4}$ Cathode Materials," Electrochimica Acta, vol. 330, pp. 135323, Jan. 2020. DOI: 10.1016/j.electacta.2019.135323.

[3] X. Si, M. Li, X. Fu. "An Improved Method to Prepare $\mathrm{FePO}_{4}$ by Introduction of $\mathrm{Na}_{3} \mathrm{PO}_{4}$ and its Usage for Fabricating $\mathrm{LiFePO}_{4}$," Journal of Wuhan University of Technology Mater. Sci. Ed., vol. 34 (5), pp. 1097-1102, Oct. 2019. DOI: 10.1007/s11595-019-2165-0.

[4] A. Kulka, K. Redel, J. Molenda. "Platelet-shape LiFePO $/ \mathrm{Fe}_{2} \mathrm{P} / \mathrm{C}$ Composite Material as a High-rate Positive Electrode for Li-ion Batteries," Solid State Ionics, vol. 335, pp. 113-120, Jul. 2019. DOI: 10.1016/j.ssi.2019.03.004.

[5] J. Li, J. Wu, Y. Li, H. Zhao, T. Zhao, S. Ma, H. Liu. "Facile Strategies to Utilize $\mathrm{FeSO}_{4} \cdot 7 \mathrm{H}_{2} \mathrm{O}$ Waste Slag for $\mathrm{LiFePO}_{4} / \mathrm{C}$ Cathode with High Performances," vol. 99, pp. 74-81, Jun. 2019. DOI: $10.1016 /$ j.jtic019.03.002.

[6] Y. Meng, Y. Li, J. Xia, Q. Hu, X. Ke, G. Ren, F. Zhu. "Fdoped LiFePO $@$ N/B/F-doped Carbon as High Performance Cathode Materials for Li-ion Batteries," Applied Surface Science, vol. 476, pp. 761-768, May 2019. DOI: 10.1016/j.apsusc.2019.01.139.

[7] L. He, W. Zha, D. Chen. "Fabrication and Electrochemical Properties of 3D Nano-network LiFePO $@$ Multiwalled Carbon Nanotube Composite Using Risedronic Acid as the Phosphorus Source," Progress in Natural Science: Materials International, vol. 29 (2), pp. 156-162, Apr. 2019. DOI: 10.1016/j.pnsc.2019.02.005.

[8] S. X. Wu, C. L. Chiang, C. C. Wang, C. Y. Chen. "Functionalization of MWCNTs by Plasma Treatment and Use as Conductive Additives for $\mathrm{LiFePO}_{4}$ Electrode," Journal of the Taiwan Institute of Chemical Engineers, vol. 89, pp. 208214, Aug. 2018. DOI: 10.1016/j.jtice.2018.04.026.

[9] G. Han, S. Yang, J. Liu, Y. Huang. "The Investigation of Humics as a Binder for $\mathrm{LiFePO}_{4}$ Cathode in Lithium Ion Battery," TMS 2018: Characterization of Minerals, Metals, and Materials 2018, pp. 31-39, Jan. 2018. DOI: 10.1007/9783-319-72484-3_4.

[10] M. Talebi-Esfandarani, S. Rousselot, M. Gauthier, P. Sauriol, M. Duttine, A. Wattiaux, Y. Liu, A. X. Sun, G. Liang, M. Dollé. "Control of the $\mathrm{LiFePO}_{4}$ Electrochemical Properties Using Low-cost Iron Precursor in a Melt Process," Journal of Solid State Electrochemistry, vol. 20 (12), pp. 3481-3490, Dec. 2016. DOI: 10.1007/s10008-016-3324-2.

[11] M. Piana, M. Arrabito, S. Bodoardo, A. D'Epifanio, D. Satolli,
F. Croce, B. Scrosati. "Characterization of Phospho-olivines as Materials for Li-ion Cell Cathodes," Ionics, vol. 8, pp. 1726, 2002. DOI: 10.1007/BF02377749.

[12] H. Yen, R. Rohan, C. Y. Chiou, C. J. Hsieh, S. Bolloju, C. C. Li, Y. F. Yang, C. W. Ong, J. T. Lee. "Hierarchy Concomitant in situ Stable Iron (II)-carbon Source Manipulation Using Ferrocenecarboxylic Acid for Hydrothermal Synthesis of $\mathrm{LiFePO}_{4}$ as High-capacity Battery Cathode," Electrochimica Acta, vol. 253 (1), pp. 227-238, Nov. 2017. DOI: 10.1016/j.electacta.2017.09.065.

[13] E. Golestani, M. Javanbakht, H. Ghafarian-Zahmatkesh, H. Beydaghi, M. Ghaemi. "Tartaric Acid Assisted Carbonization of $\mathrm{LiFePO}_{4}$ Synthesized Through in Situ Hydrothermal Process in Acqueous Glycerol Solution," Electrochimica Acta, vol. 259 (1), pp. 903-915, Jan. 2018. DOI: 10.1016/j.electacta.2017.10.123.

[14] R. Martins, R. Gonçalves, C. M. Costa, S. Ferdov, S. Lanceros-Méndez. "Mild Hydrothermal Synthesis and Crystal Morphology Control of $\mathrm{LiFePO}_{4}$ by Lithium Nitrate," NanoStructures and Nano-Objects, vol. 11, pp. 82-87, Jul. 2017. DOI: 10.1016/j.nanoso.2017.07.001.

[15] G. Wu, N. Liu, X. Gao, X. Tian, Y. Zhu, Y. Zhou, Q. Zhu. “A Hydrothermally Synthesized $\mathrm{LiFePO}_{4} / \mathrm{C}$ Composite with Superior Low-temperature Performance and Cycle Life," Applied Surface Science, vol. 435, pp. 1329-1336, Mar. 2018. DOI: 10.1016/j.apsusc.2017.11.276.

[16] W. Zhou, C. Liu, Z. Wen, J. Xu, T. Han, G. Li, D. Huang, X. Liang, Z. Lan, H. Ning, H. Huang, J. Guo. "Effects of Defect Chemistry and Kinetic Behavior on Electrochemical Properties for Hydrothermal Synthesis of $\mathrm{LiFePO}_{4} / \mathrm{C}$ Cathode Materials," Materials Chemistry and Physics, vol. 227, pp. 56-63, Apr. 2019. DOI: 10.1016/j.matchemphys.2019.01.050.

[17] Y. Zhang, P. Xin, Q. Yao. "Electrochemical Performance of $\mathrm{LiFePO}_{4} / \mathrm{C}$ Synthesized by Sol-gel Method as Cathode for Aqueous Lithium Ion Batteries," Journal of Alloys and Compounds, vol. 741, pp. 404-408, Apr. 2018. DOI: 10.1016/j.allcom.2018.01.083.

[18] M. Singh, B. Singh, M. Willert-Porada. "Reaction Mechanism and Morphology of the $\mathrm{LiFePO}_{4}$ Materials Synthesized by Chemical Solution Deposition and Solid-state Reaction," Journal of Electroanalytical Chemistry, vol. 790, pp. 11-19, Apr. 2017. DOI: 10.1016/ j.jelechem.2017.02.043.

[19] A. Lutts. "A New Method for Determining the Lattice Parameters from Powder Patterns of Orthorhombic Crystals," Zeitschrift für Kristallographie, vol. 161 (3-4), pp. 195-207, Apr. 1982. DOI: 10.1524/zkri.1982.161.3-4.195.

[20] J. B. Nelson, D. P. Riley. “An Experimental Investigation of Extrapolation Methods in the Derivation of Accurate Unit-cell Dimensions of Crystals," Proc. Phys. Soc., vol. 57, pp. 160177, 1945. DOI: 10.1088/0959-5309/57/3/302.

[21] H. M. Rietveld. "A Profile Refinement Method for Nuclear and Magnetic Structures," Journal of Applied Crystallography, vol. 2, pp. 65-71, 1969. DOI: $10.1107 /$ S0021889869006558. 